\title{
Modeling of Static Negative Bias Temperature Stressing in p-channel VDMOSFETs using Least Square Method
}

\author{
Nikola Mitrović ${ }^{1}$, Danijel Danković ${ }^{1}$, Branislav Ranđelović ${ }^{2}$,Zoran Prijićl, Ninoslav Stojadinovićc ${ }^{1,3}$ \\ ${ }^{1}$ University of Niš, Faculty of Electronic Engineering, Department of Microelectronics, Serbia \\ ${ }^{2}$ University of Niš, Faculty of Electronic Engineering, Department of Mathematics, Serbia \\ ${ }^{3}$ Serbian Academy of Sciences and Arts (SASA), Serbia
}

\begin{abstract}
Negative bias temperature instability (NBTI) is a phenomenon commonly observed in p-channel metal-oxide semiconductor (MOS) devices simultaneously exposed to elevated temperature and negative gate voltage. This paper studies threshold voltage shift under static stress associated with the NBT stress induced buildup of both interface traps and oxide trapped charge in the commercial p-channel power VDMOSFETs IRF9520, with the goal to design an electrical model. Change of threshold voltage follow power law $t^{n}$, where parameter $n$ is different depending on the stressing phase and stressing conditions. Two modeling circuits are proposed and modeling circuit elements values are analyzed. Values of modeling circuits elements are calculated using least square method approximation conducted on obtained experimental results. Modeling results of both circuits are compared with the measured results and then further discussed.
\end{abstract}

\section{Modeliranje statičnega stresa temperature zaradi negativne napetosti $v$ p-kanalnem VDMOSFETu z metodo najmanjših kvadratov}

Izvleček: Temperaturna nestabilnost pri negativni napetosti (NBTI) je fenomen p kanalnih metal-oksid polprevodnikov, ki so hkrati izpostavljeni povišani temperaturi in negativni napetosti. V študiji je opazovana sprememba pragovne napetosti komercialnega VDMOSFET tranzistorja IRF9520 pri NBT stresu in pojav naboja v spojnih in oksidnih pasteh z namenom razvoja električnega modela. Sprememba pragovne napetosti sledi zakonu moči $t^{n}$, kjer je $n$ odvisen of faze in oblike stresa. Predlagana sta dva modela, pri čemer so vrednosti elementov izračunani z metodo najmanjših kvadratov na osnovi izmerjenih vrednosti. Modelni rezultati so primerjani z meritvami.

Ključne besede: NBTI;VDMOSFET; električno vezje; modeliranje; metoda najmanjših kvadratov

*Corresponding Author's e-mail:nikola.i.mitrovic@elfak.ni.ac.rs

\section{Introduction}

As the device dimensions in CMOS technologies have been continuously scaled down, a phenomenon called Negative Bias Temperature Instability (NBTI) has gained in importance as one of the most important degradation mechanisms. Degradation of transistor parameter values due to NBTI has emerged as a major reliability concern in current and future technology generations, especially in p-channel MOSFETs [1-3]. During the stress period, the transistor parameters slowly deviate from the nominal value. Longer the stress period, higher is the impact of NBTI on transistor parameters. NBTI 
effects are manifested as the changes in device threshold voltage $\left(V_{T}\right)$, transconductance $\left(g_{m}\right)$ and drain current $\left(I_{D}\right)$, and have been observed mostly in p-channel MOSFETs operated under negative gate oxide fields in the range $2-6 \mathrm{MV} / \mathrm{cm}$ at temperatures around $100{ }^{\circ} \mathrm{C}$ or higher [1-5]. Change in these parameters is dependent on the stress parameters (time, temperature, gate voltage). Considering the effects of NBTI related degradation on device electrical parameters, NBT stressinduced threshold voltage shift $\left(\Delta V_{T}\right)$ seems to be the most critical one $[6,7]$.

Despite notable scale down in the device dimensions, ultra-thick gate oxide reliability studies are still of significance because of broad use of MOS technology. Taking this into consideration, our earlier papers were dealing with NBTI in p-channel power vertical double diffused MOS (VDMOS) transistors [6, 8-13]. Their reliability has been investigated under various stress conditions, such as irradiation, high electric field, NBTI, NBTI under low magnetic field, and NBTI and irradiation [1316]. NBTI is critical for normal operation of power MOSFETs since they are routinely operated at high current and voltage levels, which lead to both increased gate oxide fields and self-heating, thus favor NBTI.

First thorough explanation of processes on negative bias temperature instabilities was made by Jeppson and Svensson [17]. Even though more than 40 years have passed since then, many mechanisms of NBTI are not very well understood yet. In the last decade, many different working groups are addressing NBTI effects, with accent on both description and modeling of voltage threshold shifts $[19,20]$. Swami presented a model for nano MOSFET for FinFET technologies [20], while Aleksandrov reported a model that is based on a reaction-diffusion principle [21]. Still, an appropriate electrical model to describe instabilities corresponding to different stressing conditions is lacking [22]. A model by Danković is RC based model and describes both static and pulsed NBT stressing [23]. However, further mathematical improvements are needed in order to overcome time-bounded flaws of the model, and to make use of the dependencies between temperatures and bias values. Ma presented a model that attempts to explore these dependencies [24], although they aren't analyzed on the accelerated NBT stressing conditions. Maricau used similar approach of RC based model [25], but it analyses short stressing periods, while this paper focuses on modeling of the effects caused by longer stressing periods.

The use of this type modeling is to create a model that can be mathematically calculated in order to incorporate the model into SPICE. That will enable the design- ers to consider these instabilities of the circuit during the design phase.

The primary part of this study is to propose an equivalent electrical circuit for modeling of $\Delta V_{T}$ based on experimental data using least square method. In the section 2, experimental setup and results will be briefly described and discussed. Section 3 deals with the modeling approach, and evaluates the model and gives comparison between measured and modeled results.

\section{Experimental setup}

Used devices for this research are commercial p-channel power VDMOSFETs IRF9520 with initial threshold voltage of $V_{T O}=-3.6 \mathrm{~V}$ [26]. Devices are built in standard silicon-gate technology with $100 \mathrm{~nm}$ thick gate oxide and packed in plastic TO-220 packages.

To properly investigate NBTI in p-channel power VD-MOS transistors in which gate oxides thickness are $100 \mathrm{~nm}$, special stress voltages are needed. These voltages need to be several times larger than typical operating voltage of these transistors (more than - $40 \mathrm{~V}$ ). To ensure these specific signals, it is needed to develop an additional separate circuit that provides appropriate higher stress voltages for stressing. In years during the research, we have developed a system that automates both NBT stress and measurement on $\mathrm{p}$-channel power VDMOS transistors [12].

System consists of high voltage stress circuit and of low voltage measurement circuit that are controlled with software-controlled switches. Stressing circuit includes an external amplifier between the stress voltage source unit and the device under test (DUT). The transfer I-V characteristics were measured at the drain voltage value of $100 \mathrm{mV}$, so the device was kept in the linear region of operation. Gate voltage was swept from -2 to $-4.75 \mathrm{~V}$, with $-50 \mathrm{mV}$ step. Designed system allows full range measurement of transfer I-V characteristics, that is used to extract threshold voltage using second derivative method [27]. This measurement method has previously been used by several research groups [9-13, $15,16]$.

Several sets of $\mathrm{p}$-channel devices were tested under different conditions. Devices were subjected to stress for 24 hours during which 36 interim measurements were performed. Two different negative voltages were applied to gate (- $45 \mathrm{~V}$ and $-50 \mathrm{~V}$ ) while source and drain terminals were grounded. Experiments were done at two different temperatures $\left(150^{\circ} \mathrm{C}\right.$ and $\left.175^{\circ} \mathrm{C}\right)$ and values of threshold voltage shifts are obtained. Our ear- 
lier experiments included testing devices under many different conditions in terms of both gate voltage and temperature [9-13]. Experimental results are given in Figure 1. For the comprehensiveness of the proposed model, only four combinations of stress conditions are shown.

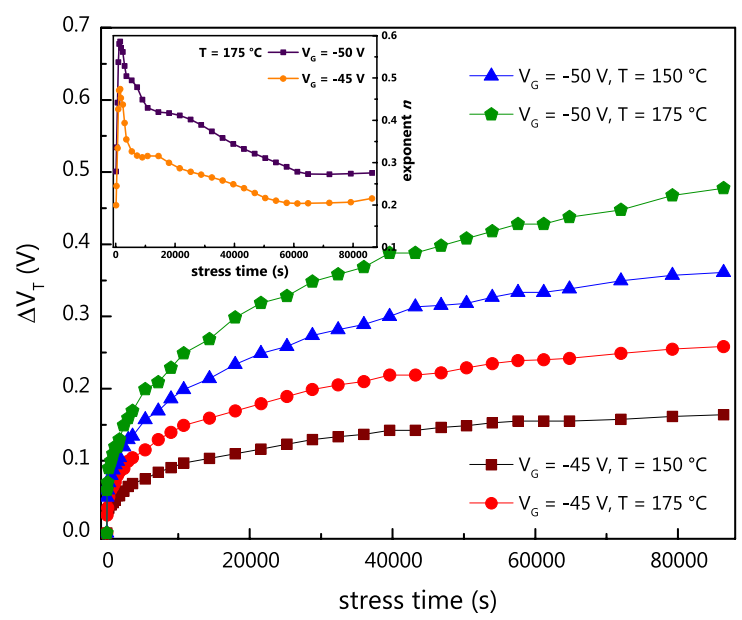

Figure 1: Threshold voltage shifts caused by static NBT stress with value of parameter $n$ during stressing.

NBT stress under static conditions results in notable threshold voltages shifts. These changes become more pronounced at higher stress voltages and temperatures, which is in line with other investigations [18, 22, $28,29]$. A lot of results, including ours indicate that $\Delta V_{T}$ saturates with increase in stress time $[4,6,11]$.

NBT stress causes threshold voltage shifts with widely different rate in different time periods [28, 29]. Evolution of $\Delta V_{T}$ through time is presented in Figure 1 Inserted graphic, and given with power law $\left(t^{n}\right)$. During this evolution, distinct phases can be distinguished [4, 13, 30]. For every phase, the value of parameter $n$ is different. Through each of the phases, parameter $n$ is as close as constant (not exactly constant, but in the very limited range). During our earlier researches that involved extensive NBT stress [4, 6, 8, 9-13], in the case of long-term experiments, three different phases are detected in evolution of $n$ [6]. Starting phase, where $n=0.4$. In this phase, $n$ is highly dependent on the stressing temperature and bias $[4,6]$. Second phase, where $n$ drops to $n=0.25$, and is almost independent on stressing conditions. Third, final phase, where $n$ in again dependent on the stressing conditions and steadily declines to $n=0.14$, continuing to saturation. Similar results are obtained for all stressing temperatures in the experiments. All of the results are suggesting similar development of the parameter $n[6$, $13,31]$. So, it can be concluded that parameter $n$ is overall higher at the start phase of the stressing, but tends to saturate in later phases of stressing.
Described progress of the parameter $n$ is caused by originated oxide trapped charge and interface traps, which directly influence the changes in the threshold voltage during NBT stress [4]. These occurrences are product of numerous electrochemical processes and reactions concerning oxide and interface defects, holes and other and species related to hydrogen. Depending on the stressing conditions and the number of defects, these reactions can occur in either forward or reverse direction. Since reversed reactions are characteristic for recovery of the degradation that occurs during pulsed stressing, in the case of static stress, forward reactions are dominant [4]. Starting phase of stressing, which explain creation of interface traps is explained with the reaction:

$$
S i_{3} \equiv S i-H \leftrightarrow S i_{3} \equiv S i^{\bullet}+H^{\bullet}
$$

The released hydrogen atoms $\left(H^{*}\right)$ are highly reactive, and they also can dissociate the $\mathrm{SiH}$ bonds at the interface or in the oxide near the interface. These reactions lead to creation of additional interface traps or positively charged oxide defects.

$$
\begin{aligned}
& S i_{3} \equiv S i-H+H^{\bullet} \leftrightarrow S i_{3} \equiv S i \cdot+H_{2} \\
& O_{3} \equiv S i-H+H^{\cdot}+h^{+} \leftrightarrow O_{3} \equiv S i^{+}+H_{2}
\end{aligned}
$$

Released unstable hydrogen atoms react with the holes to form ions.

$$
H^{\cdot}+h^{+} \rightarrow H^{+}
$$

However, hydrogen ions also dissociate $\mathrm{SiH}$ bonds in the oxide near the interface leading to creation of positively charged oxide defects.

$$
\mathrm{O}_{3} \equiv \mathrm{Si}-\mathrm{H}+\mathrm{H}^{+} \leftrightarrow \mathrm{O}_{3} \equiv \mathrm{Si}^{+}+\mathrm{H}_{2}
$$

Oxide trapped charge and interface traps buildup described in the given reactions is notably enhanced in the early phase while concentration of $\mathrm{SiH}$ trap precursors is still high. As the stress time increases, the number of both positively charged defects and interface traps is getting higher. However, probability for reverse reaction (passivation processes) occurring rises as well.

The $\mathrm{H}_{2}$ molecules released in reactions (2), (3) and (5) diffuse deeper into oxide and can be cracked at positively charged oxide traps:

$$
\mathrm{O}_{3} \equiv \mathrm{Si}^{+}+\mathrm{H}_{2} \rightarrow \mathrm{O}_{3} \equiv \mathrm{Si}-\mathrm{H}^{+}+\mathrm{H}^{\cdot}
$$

As a product of reaction (6), $H^{\cdot}$ is released. It can take part in either forward reaction or reverse reaction, thereby rounding the chain of reaction. Increased amount of reverse reaction occurences lead to change in the slope of a function interpreting parameter $n$. Key step for appropriate modeling is to tackle the change of parameter $n$ in phases, in order to follow the evolution of $\Delta V_{T}$. 


\section{Modeling approach}

Analytical models for NBT stressing have been researched throughout the years [19-25, 32-37]. This model assumes continuous stress on the PMOS devices. Model is built to follow $\Delta V_{T}$ during stress time. Since the change of $\Delta V_{T}$ is given with the power law $\left(t^{n}\right)$, a capacitor $C$ charged through resistor $R$ is chosen for the central element of the modeling circuit. Capacitor charging equation is given with:

$V_{C}=V_{S}\left(1-e^{-\frac{t}{\tau}}\right)$

Capacitor is chosen because the capacitor voltage is given in exponential form, which is a type of the power law, needed for $\Delta V_{T}$ modeling. So, the capacitor voltage, $V_{c}$ models $\Delta V_{T}$. In given modeling circuit, rise of the capacitor voltage should correspond to the rise of the $\Delta V_{T}$, so that in any moment $t_{1}, V_{c}$ should be as much as accurate as $\Delta V_{T}$. To accomplish that, specific controlled charging rate of the capacitor must be achieved. Value of time constant, $\tau$, must be calculated first, and then values of capacitance of capacitor $C$ and resistance of the resistor $R$ must be fitted. Value of $V_{s}$ is acquired using stretch exponential (SE) equations $[3,6]$ and listed in Table 1. The SE fit predicts that value of $\Delta V_{T}$ will saturate after extended stressing and it estimates the saturation value. Increased stressing time leads to better estimation of the saturation value, as can be seen for parameter $n$. Stretch exponential equation is given with:

$$
\Delta V_{T}(t)=\Delta V_{T \max } \Delta\left[1-e^{-\left(\frac{t}{\tau_{0}}\right)^{\beta}}\right]
$$

In the equation (8), $\beta, \tau_{0}$ and $\Delta V_{T \max }$ are fitting parameters. Parameter $\beta$ is defined as a distribution width, and $\tau_{0}$ represents a characteristic time constant of the distribution. Parameter $\Delta V_{T \max }$ is a value of $\Delta V_{T}$ saturation $[6,42]$. Value of $V_{S}$ is actually value of $\Delta V_{T \max }$ given in equation 8. Through this value, dependence of the modeling results on bias and temperature values is given. Therefore, for different stressing conditions, value of $V_{s}$ is different as well. Although at first this looks as a serious limitation, based on our earlier studies, it is possible to estimate the interdependence of time, voltage, temperature and $\Delta V_{T}$ of investigated VDMOSFETs using the results obtained by accelerated NBT stressing $[39,40]$.

To do modeling based on experimental data, it is needed to find a function that describes experimen- tal data sets, and then to calculate modeling circuit element values based on a fitting function parameter. Most appropriate method for this fitting is Least Square Method (LSM) [41]. LSM is one of the most widely used method to find or estimate the numerical values of the parameters.

Table 1: Values of $V_{s}$ for different stressing conditions calculated by $\mathrm{SE}$ equations.

\begin{tabular}{|l|c|c|}
$\begin{array}{l}\text { Stressing } \\
\text { Temperature }\left[{ }^{\circ} \mathrm{C}\right]\end{array}$ & $\begin{array}{c}\text { Stressing } \\
\text { Voltage }[\mathrm{V}]\end{array}$ & $\begin{array}{c}\text { Value of } \mathrm{V}_{\mathrm{S}} \\
{[\mathrm{V}]}\end{array}$ \\
\hline 150 & -45 & 0.182 \\
\cline { 2 - 3 } & -50 & 0.395 \\
\hline 175 & -45 & 0.312 \\
\cline { 2 - 3 } & -50 & 0.513 \\
\hline
\end{tabular}

It can also be used to fit a function to a set of data and to characterize the statistical properties of the estimates [42-44]. LSM is a mathematical method for finding the best-fitting curve to a given set of points by minimizing the sum of the squares of the offsets of the points from the curve. Basic principle of the LSM implies that a set of I pairs of data points given with $\left(x_{1}, y_{1}\right),\left(x_{2}, y_{2}\right), \ldots$ $\left(x_{i}, y_{i}\right)$ is used to find a function that describes dependence of $y$ from independent variables $x$. A curve that is created from the experimentally measured data points can be presented in the generic power form given as:

$y^{*}=A \cdot t^{B}$

In equation (9), $y^{*}$ represent modeled function, while $A$ and $B$ are free fitting parameters. This form of the modeling function is the most suitable one since the parameter $t^{n}$ that should be relevant with modeled data also has power evolution. Parameters $A$ and $B$ specify the slope of the modeling function and determine the regression line. LSM defines the estimate of these parameters as the value which minimizes the sum of squares between the measurement $(y)$ and the model $\left(y^{*}\right)$ which leads to expression:

$\varepsilon=\sum_{i}\left(y_{i}-y_{i}^{*}\right)^{2}=\sum_{i}\left(y_{i}-\left(A \cdot t^{B}\right)\right)^{2}$

In the equation (10), $\varepsilon$ stands for error which is a value to be minimized. The most suitable way to calculate parameters $A$ and $B$ is to introduce matrix notation in the following way:

$\vec{a}=\left[\begin{array}{l}A \\ B\end{array}\right]$ 


$$
\begin{aligned}
X & =\left[\begin{array}{cc}
1 & x_{1} \\
1 & x_{2} \\
1 & x_{3} \\
\vdots & \vdots \\
1 & x_{i}
\end{array}\right] \\
G & =\left[\begin{array}{c}
\ln f\left(x_{1}\right) \\
\ln f\left(x_{2}\right) \\
\ln f\left(x_{3}\right) \\
\vdots \\
\ln f\left(x_{i}\right)
\end{array}\right]
\end{aligned}
$$

Vector $\vec{a}$ consists of the parameters that need to be calculated. Matrix $X$ is created from the time points when the measurements were done, while the matrix $G$ consists of logarithm of values being measured in the time points. Calculation of a vector $\vec{a}$ is given with the equation:

$\vec{a}=\left(X^{T} X\right)^{-1} X^{T} \cdot G$

After performing matrix calculus for different stressing conditions, parameters $\mathrm{A}$ and $\mathrm{B}$ are calculated and given in the Table 2.

Table 2: Calculated parameters $A$ and $B$ for different NBTS conditions.

\begin{tabular}{|l|c|c|c|}
$\begin{array}{l}\text { Stressing } \\
\begin{array}{l}\text { Temperature } \\
{\left[{ }^{\circ} \mathrm{C}\right]}\end{array}\end{array}$ & $\begin{array}{c}\text { Stressing } \\
\text { Voltage } \\
{[\mathrm{V}]}\end{array}$ & $\begin{array}{c}\text { Parameter } \\
\mathrm{A}\end{array}$ & $\begin{array}{c}\text { Parameter } \\
\mathrm{B}\end{array}$ \\
\hline 150 & -45 & 0.00772 & 0.27032 \\
\cline { 2 - 4 } & -50 & 0.01254 & 0.29692 \\
\hline \multirow{2}{*}{175} & -45 & 0.00798 & 0.31088 \\
\cline { 2 - 4 } & -50 & 0.01453 & 0.30617 \\
\hline
\end{tabular}

After acquiring fitting parameters, A and B, it is needed to equalize equation (9) with the equation that describes capacitor charging (7). Even though it is mathematically simpler to use exponential form with least square approximation, negative exponent in the capacitor charging formula reverses the convexity of the function. Reversed convexity can introduce a lot of mathematical problems, delivering inadequate poor modeling results. After solving equations, variable $\tau$ is calculated. However, even after that calculation is concluded, problem of calculating precise resistance $R$ and capacitance $C$ that compose $\tau$ still remains. For mod- eling purpose, value of capacitance is set to $1 \mathrm{mF}$. Basic modeling circuit is given in Figure 2.

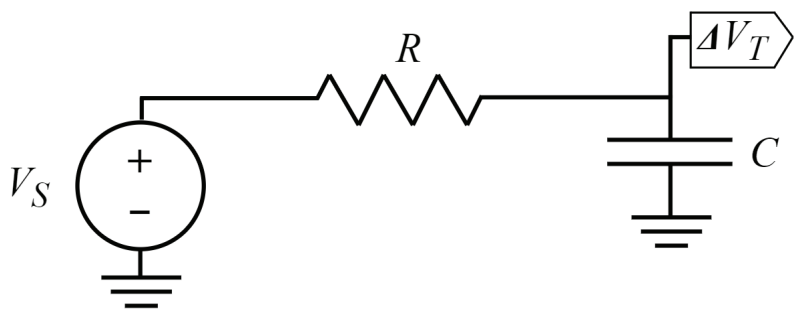

Figure 2: Basic RC circuit for $\Delta V_{T}$ modeling.

Since the variety of the time constants can be found in the progress of the $\Delta V_{T}$, modeling with only one specific RC connection could lead to considerable dissent in the particular parts of the curve. Parameters $A$ and $B$ are calculated for the full period of stressing time.

The concept of improved modeling is to present the experimental curve as the product of multiple parts. These parts are to be determined by the phases of parameter $n$ evolution, in favor of increasing of the accuracy of the model. To conduct this improvement, additions to the modeling circuit must be made. To follow evolution of $\Delta V_{T}$, charging rate of the capacitor is to be different in different time intervals. A method for enabling charging rate diversity is to increase the number of RC connections. With the range of different time constants, capacitor voltage can adapt more precisely to $\Delta V_{T}$. Adding switches and enabling only specific RC connections in determined time periods leads to capacitor voltage being additionally determined. Greater number of RC connections can be achieved in multiple ways, either by increasing number of resistors that are charging one capacitor, either by increasing number of capacitors that are charged through one resistor or either by increasing number of both resistors and capacitors. Since the principle of this modeling is that capacitor voltage models $\Delta V_{T^{\prime}}$ number of capacitors is set to one. This way, complicate procedure of summing of capacitor voltages that corresponds to $\Delta V_{T}$ in different time periods is avoided, while concept is sustained. With only one capacitor, only way to increase number of RC connections is with increasing number of resistors.

With the goal to link phases of degradation with number of RC connections, modeling circuit is expanded with two additional resistors and switches. Expanded circuit is given in Figure 3.

In the starting moment, both switches, $S_{1}$ and $S_{2}$ are closed. Capacitor $C$ is charged through all of three resistors. Since the resistors are connected in parallel, equivalent resistance is lower than the resistance of the 


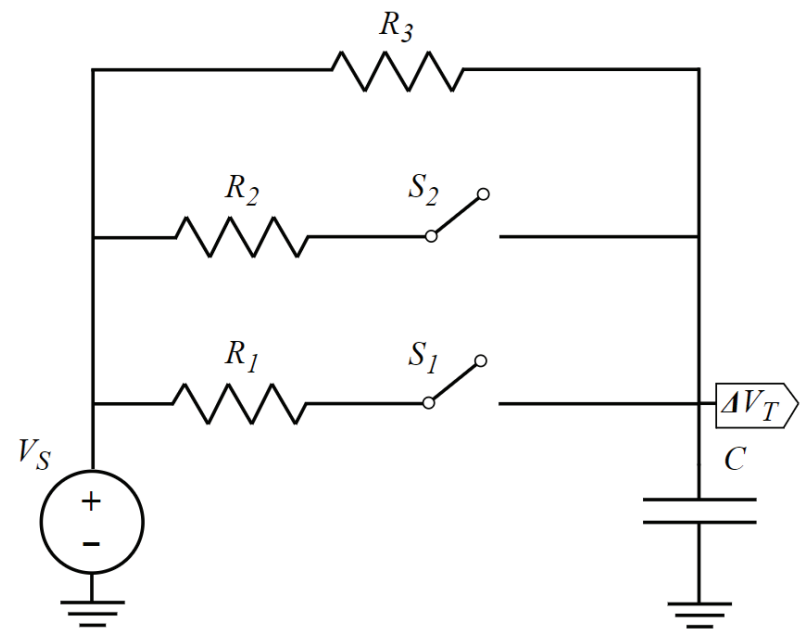

Figure 3: Expanded circuit for modeling of static stress.

resistor with lowest resistance. Growth of $\Delta V_{T}$ is largest in starting phase of stressing, so the capacitor $C$ is charged through lowest resistance, which is in line with model expectations. After starting phase, switch $S_{1}$ opens, so that capacitor $C$ continues to charge through parallel resistance of resistors $R_{2}$ and $R_{3}$ only.

To provide suitable results and follow properly $\Delta V_{T^{\prime}}$ it is important that $R_{3}>R_{2}>R_{1}$. That way, equivalent resistance of resistors $R_{2}$ and $R_{3}$ is greater than the equivalent resistance of all three resistors. After opening switch $S_{1}$, capacitor is charged through higher resistance than before opening the switch, leading to slower capacitor charging and lower slope of the charging curve.

Higher charging resistance leads to even slower charging, which is, once again, in line with the model expectations, and describes development of $\Delta V_{T}$ during stressing. To find appropriate values of resistance LSM is used again. This time, every phase is approximated separately, LSM is applied 12 more times, leading to parameters $A_{1}, A_{2}, A_{3}$ and $B_{1}, B_{2}$ and $B_{3}$. According to these parameters and in consideration with equivalent resistance equations, resistance of resistors $R_{1}, R_{2}$ and $R_{3}$ are calculated. Results of different stressing conditions are given in the Table 3. Error of the estimated parameter is calculated using R-squared method and is between 0.95043 and 0.98268 for modeling with basic circuit and between 0.98764 and 0.99262 for modeling with expanded circuit. Modeled results using expanded modeling circuit are given in Figure 4 and 5.

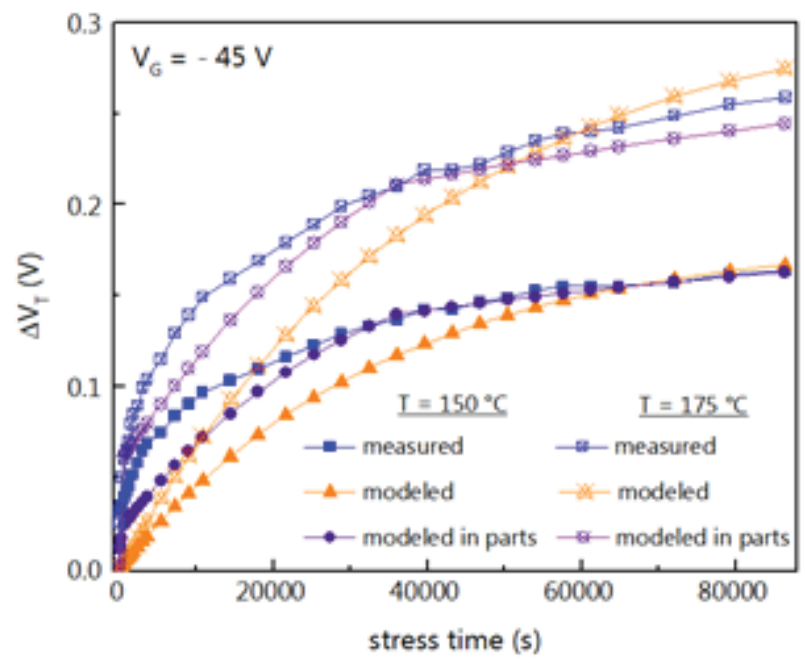

Figure 4: Values of $\Delta V_{T}$ obtained by measuring and with modeling for $\mathrm{T}=150{ }^{\circ} \mathrm{C}$ and for $\mathrm{T}=175^{\circ} \mathrm{C}$ where $V_{G}=-45 \mathrm{~V}$.

Results given in the Figure 4 and Figure 5 show that modeling error is considerably reduced if the modeling is done with taking in mind phase division of the pa-

Table 3: Values od parameters $A_{1}-A_{3^{\prime}} B_{1}-B_{3}$ and resistances $R_{1}-R_{3}$ for different stressing conditions.

\begin{tabular}{|c|c|c|c|c|}
\hline \multirow{2}{*}{$\begin{array}{l}\text { Stressing Temperature }\left[{ }^{\circ} \mathrm{C}\right] \\
\text { Stressing Voltage }[\mathrm{V}]\end{array}$} & \multicolumn{2}{|c|}{150} & \multicolumn{2}{|c|}{175} \\
\hline & -45 & -50 & -45 & -50 \\
\hline \multicolumn{5}{|l|}{ Phase $1(0<t<600 \mathrm{~s})$} \\
\hline A1 & 0.02191 & 0.02191 & 0.00544 & 0.00475 \\
\hline B1 & 0.08548 & 0.20024 & 0.38145 & 0.53067 \\
\hline $\mathrm{R} 1[\mathrm{M} \Omega]$ & 10.1215 & 2.9499 & 2.9304 & 3.2873 \\
\hline \multicolumn{5}{|l|}{ Phase $2(600 \mathrm{~s}<\mathrm{t}<36000 \mathrm{~s})$} \\
\hline $\mathrm{A} 2$ & 0.00504 & 0.00926 & 0.00793 & 0.01092 \\
\hline B2 & 0.31566 & 0.32872 & 0.31336 & 0.33571 \\
\hline R2 [MS] & 46.7246 & 71.4286 & 56.5297 & 82.6446 \\
\hline \multicolumn{5}{|c|}{ Phase $3(36000 \mathrm{~s}<\mathrm{t}<86400 \mathrm{~s})$} \\
\hline A3 & 0.01731 & 0.02279 & 0.01754 & 0.01857 \\
\hline B3 & 0.19832 & 0.24382 & 0.23718 & 0.28539 \\
\hline R3 [M 2$]$ & 87.8942 & 58.7951 & 128.9552 & 53.6646 \\
\hline
\end{tabular}




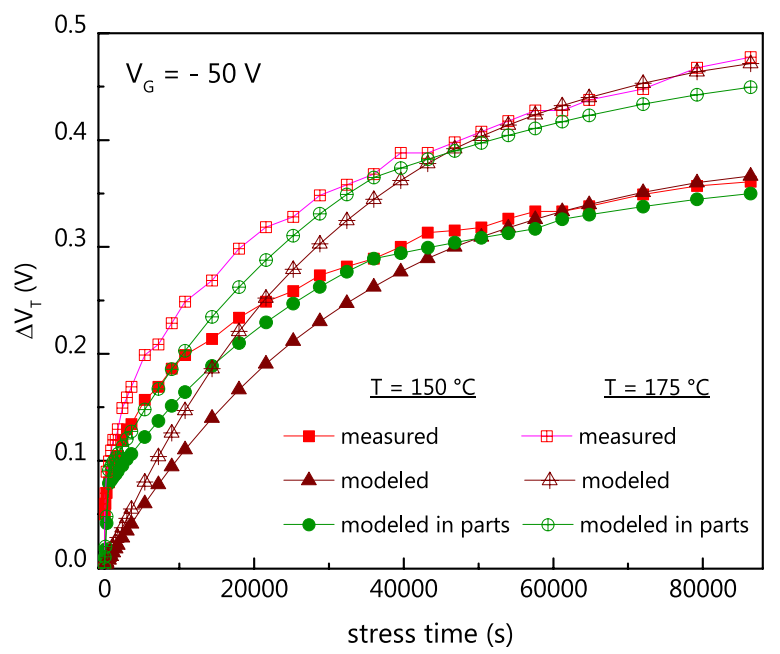

Figure 5: Values of $\Delta V_{T}$ obtained by measuring and with modeling for $\mathrm{T}=150{ }^{\circ} \mathrm{C}$ and for $\mathrm{T}=175^{\circ} \mathrm{C}$ where $V_{G}=-50 \mathrm{~V}$.

rameter $n$ evolution. This is notable especially during the second phase of $\Delta V_{T}$ development. Since the third phase occurs after approximately 10 hours of stressing $[6,38]$, during the experiment, samples are subdued to this phase the longest. When approximating full range of experimental data, LSM adapts parameters better for the longest lasting phase, and thereby, creating a slightly greater mismatch for the rest of the data. With this type of phase division, modeling error is more than twice decreased, as can be seen in Figure 6.

Figure 6: Difference in absolute errors of proposed modeling approaches for $\mathrm{T}=150{ }^{\circ} \mathrm{C}$ and $V_{G}=-45 \mathrm{~V}$.

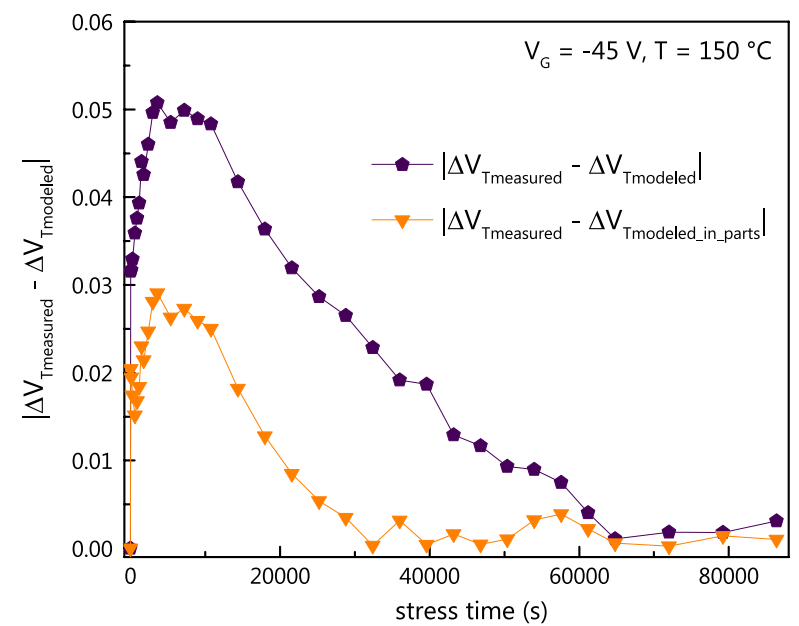

Results given in Figure 6 show that modeling error has very similar form to the evolution of the parameter $n$, given in the Figure 1 (inserted graphic), which is fundamental signature of NBTI. With additional resistors and switches, used in the expanded modeling circuit, slope of the curve that shows modeling error is decreased (peak of the error is reduced by half, and error is reduced even more in the other parts of the curve). This result is in line with the modeling approach. Further expansion of the circuit (adding more RC connections, and splitting degradation phases into more phases that are shorter, would impact in even more decreased slope).

However, even with further increase in number of resistors, in the specific shorter time interval, time constant will be uniform. To design even more accurate model, number of RC connections is to depend not only on stressing time or phase, but on the actual numbers of individual defects in the circuit itself [29]. With increasing the number of defects, number of RC connections rises, thereby increases the overall sum of the voltages that comprise $\Delta V_{T}$.

\section{Conclusions}

Impacts of static negative bias temperature stressing in p-channel power VDMOSFETs IRF9520 have been reported. An equivalent electrical circuit is designed in order to model the behavior of $\Delta V_{T}$. Mathematical method of least square approximation is described and conducted to determine and to acquire parameters for values of modeling circuit elements. Phase division of parameter $n$ evolution during modeling leads to better overall results in terms of accuracy and precision, regardless of stressing conditions. Future steps of work include improving the model with adapting it to the modeling of pulsed stress as well, since $p$-channel power VDMOSFETs are widely used in switching circuits because of their good switching characteristics.

\section{Acknowledgments}

This work has been supported by the Ministry of Education, Science and Technological Development of the Republic of Serbia and in part by the Serbian Academy of Science and Arts.

\section{Conflict of Interest}

The author declares no conflict of interest. The founding sponsors had no role in the design of the study; in the collection, analyses, or interpretation of data; in the writing of the manuscript, and in the decision to publish the results 


\section{References}

1. Ogawa, S., Shimaya, M., \& Shiono, N. (1995). Interface-trap generation at ultrathin $\mathrm{SiO} 2(4-6 \mathrm{~nm})-\mathrm{Si}$ interfaces during negative-bias temperature aging. Journal of Applied Physics, 77(3). https://doi.org/10.1063/1.358977

2. Schroder, D. K., \& Babcock, J. A. (2003). Negative bias temperature instability: Road to cross in deep submicron silicon semiconductor manufacturing. Journal of Applied Physics, 94(1). https://doi.org/10.1063/1.1567461

3. Stathis, J. H., \& Zafar, S. (2006). The negative bias temperature instability in MOS devices: A review. Microelectronics Reliability, 46(2-4), 270-286. https://doi.org/10.1016/j.microrel.2005.08.001

4. Stojadinović, N., Danković, D., Djorić-Veljković, S., Davidović, V., Manić, I., \& Golubović, S. (2005). Negative bias temperature instability mechanisms in p-channel power VDMOSFETs. Microelectronics Reliability, 45(9-11), 1343-1348. https://doi.org/10.1016/j.microrel.2005.07.018

5. Grasser, T., Aichinger, T., Pobegen, G., Reisinger, H., Wagner, P. J., Franco, J., Nelhiebel, M., \& Kaczer, B. (2011). The "permanent" component of NBTI: Composition and annealing. IEEE International Reliability Physics Symposium Proceedings, 6A.2.1-6A.2.9.

https://doi.org/10.1109/IRPS.2011.5784543

6. Danković, D., Manić, I., Djorić-Veljković, S., Davidović, V., Golubović, S., \& Stojadinović, N. (2006). NBT stress-induced degradation and lifetime estimation in p-channel power VDMOSFETs. Microelectronics Reliability, 46(9-11), 1828-1833. https://doi.org/10.1016/j.microrel.2006.07.077

7. Saluja, K. K., Vijayakumar, S., Sootkaneung, W., \& Yang, X. (2008). NBTI degradation: A problem or a scare? Proceedings of the IEEE International Frequency Control Symposium and Exposition, 137-142.

https://doi.org/10.1109/VLSI.2008.43

8. Stojadinović, N., Manić, I., Davidović, V., Danković, D., Djorić-Veljković, S., Golubović, S., \& Dimitrijev, S. (2003). Effects of electrical stressing in power VDMOSFETs. 2003 IEEE Conference on Electron Devices and Solid-State Circuits, EDSSC 2003, 291-296.

https://doi.org/10.1109/EDSSC.2003.1283534

9. Danković, D., Manić, I., Prijić, A., Djorić-Veljković, S., Davidović, V., Stojadinović, N., Prijić, Z., \& Golubović, S. (2015). Negative bias temperature instability in p-channel power VDMOSFETs: Recoverable versus permanent degradation. Semiconductor Science and Technology, 30(10). https://doi.org/10.1088/0268-1242/30/10/105009
10. Manić, I., Danković, D., Prijić, A., Davidović, V., Djorić-Veljković, S., Golubović, S., Prijić, Z., \& Stojadinović, N. (2011). NBTI related degradation and lifetime estimation in $\mathrm{p}$-channel power VDMOSFETs under the static and pulsed NBT stress conditions. Microelectronics Reliability, 51(9-11), 1540-1543.

https://doi.org/10.1016/j.microrel.2011.06.004

11. Danković, D., Manić, I., Prijić, A., Davidović, V., Djorić-Veljković, S., Golubović, S., Prijić, Z., \& Stojadinović, N. (2013). Effects of static and pulsed negative bias temperature stressing on lifetime in p-channel power VDMOSFETs. Informacije MIDEM, 43(1), 58-66.

12. Manić, I., Danković, D., Prijić, A., Prijić, Z., \& Stojadinović, N. (2014). Measurement of NBTI degradation in p-channel power VDMOSFETs. Informacije MIDEM, 44(4), 280-287.

13. Danković, D., Manić, I., Davidović, V., Prijić, A., Marjanović, M., Ilić, A., Prijić, Z., \& Stojadinović, N. D. (2016). On the recoverable and permanent components of NBTI in p-channel power VDMOSFETs. IEEE Transactions on Device and Materials Reliability, 16(4), 522-531. https://doi.org/10.1109/TDMR.2016.2598557

14. Tahi, H., Tahanout, C., Boubaaya, M., Djezzar, B., Merah, S. M., Nadji, B., \& Saoula, N. (2017). Experimental Investigation of NBTI Degradation in Power VDMOS Transistors under Low Magnetic Field. IEEE Transactions on Device and Materials Reliability, 17(1), 99-105.

https://doi.org/10.1109/TDMR.2017.2666260

15. Davidović, V., Danković, D., Ilić, A., Manić, I., Golubović, S., Djoric-Veljković, S., Prijić, Z., \& Stojadinović, N. (2016). NBTI and Irradiation Effects in P-Channel Power VDMOS Transistors. IEEE Transactions on Nuclear Science, 63(2), 12681275.

https://doi.org/10.1109/TNS.2016.2533866

16. Davidović, V., Danković, D., Golubović, S., Djorić-Veljković, S., Manić, I., Prijić, Z., Prijić, A., Stojadinović, N., \& Stanković, S. (2018). NBT stress and radiation related degradation and underlying mechanisms in power VDMOSFETs. Facta Universitatis - Series: Electronics and Energetics, 31(3), 367-388.

https://doi.org/10.2298/fuee1803367d

17. Jeppson, K. O., \& Svensson, C. M. (1977). Negative bias stress of MOS devices at high electric fields and degradation of MNOS devices. Journal of Applied Physics, 48(5).

https://doi.org/10.1063/1.323909

18. Parihar, N., Goel, N., Chaudhary, A., \& Mahapatra, S. (2016). A Modeling Framework for NBTI Degradation Under Dynamic Voltage and Frequency 
Scaling. IEEE Transactions on Electron Devices, 63(3), 946-953.

https://doi.org/10.1109/TED.2016.2519455

19. Zeng, Y., Li, X.-J., Qing, J., Sun, Y.-B., Shi, Y.-L., Guo, A., \& Hu, S.-J. (2017). Detailed study of NBTI characterization in 40-nm CMOS process using comprehensive models. Chinese Physics B, 26(10), 108503.

https://doi.org/10.1088/1674-1056/26/10/108503

20. Swami, Y., \& Rai, S. (2019). Ultra-Thin High-K Dielectric Profile Based NBTI Compact Model for Nanoscale Bulk MOSFET. Silicon, 11, 1661-1671. https://doi.org/10.1007/s12633-018-9984-z

21. Aleksandrov, O. V. (2020). Model of the NegativeBias Temperature Instability of p-MOS Transistors. Semiconductors, 54, 233-239. https://doi.org/10.1134/S1063782620020037

22. Stathis, J. H., Mahapatra, S., \& Grasser, T. (2018). Controversial issues in negative bias temperature instability. Microelectronics Reliability, 81(November 2017), 244-251. https://doi.org/10.1016/j.microrel.2017.12.035

23. Danković, D., Mitrović, N., Prijić, Z., \& Stojadinović, N. D. (2020). Modeling of NBTS Effects in P-Channel Power VDMOSFETs. IEEE Transactions on Device and Materials Reliability, 20(1), 204-213. https://doi.org/10.1109/TDMR.2020.2974131

24. Ma, C., Mattausch, H. J., Matsuzawa, K., Yamaguchi, S., Hoshida, T., Imade, M., Koh, R., Arakawa, T., \& Miura-Mattausch, M. (2014). Universal NBTI compact model for circuit aging simulation under any stress conditions. IEEE Transactions on Device and Materials Reliability. https://doi.org/10.1109/TDMR.2014.2322673

25. Maricau, E., Zhang, L., Franco, J., Roussel, P., Groeseneken, G., \& Gielen, G. (2011). A compact NBTI model for accurate analog integrated circuit reliability simulation. European Solid-State Device Research Conference. https://doi.org/10.1109/ESSDERC.2011.6044213

26. IRF9520, Data sheet, "International Rectifier," /Online/. Available: http://www.irf.com, 1998.

27. Ortiz-Conde, A., García Sánchez, F. J., Liou, J. J., Cerdeira, A., Estrada, M., \& Yue, Y. (2002). A review of recent MOSFET threshold voltage extraction methods. Microelectronics Reliability, 42(4-5), 583-596.

https://doi.org/10.1016/S0026-2714(02)00027-6

28. Grasser, T. (2014). Bias temperature instability for devices and circuits. In Bias Temperature Instability for Devices and Circuits.

https://doi.org/10.1007/978-1-4614-7909-3

29. Reisinger, H., Grasser, T., Gustin, W., \& Schlünder, C. (2010). The statistical analysis of individual defects constituting NBTI and its implications for modeling DC- and AC-stress. IEEE International Reliability Physics Symposium Proceedings, 7-15. https://doi.org/10.1109/IRPS.2010.5488858

30. Aono, H., Murakami, E., Okuyama, K., Nishida, A., Minami, M., Ooji, Y., \& Kubota, K. (2005). Modeling of NBTI saturation effect and its impact on electric field dependence of the lifetime. Microelectronics Reliability, 45(7-8), 1109-1114.

https://doi.org/10.1016/j.microrel.2004.12.015

31. Stojadinović, N., Manić, I., Danković, D., DjorićVeljković, S., Davidović, V., Prijić, A., Golubović, S., \& Prijić, Z. (2014). Negative bias temperature instability in thick gate oxides for power MOS transistors. In Bias Temperature Instability for Devices and Circuits (pp. 533-559). https://doi.org/10.1007/978-1-4614-7909-3 20

32. Alam, M. A., \& Mahapatra, S. (2005). A comprehensive model of PMOS NBTI degradation. Microelectronics Reliability, 45(1), 71-81. https://doi.org/10.1016/j.microrel.2004.03.019

33. Mahapatra, S., Goel, N., Desai, S., Gupta, S., Jose, B., Mukhopadhyay, S., Joshi, K., Jain, A., Islam, A. E., \& Alam, M. A. (2013). A comparative study of different physics-based NBTI models. IEEE Transactions on Electron Devices, 60(3), 901-916.

https://doi.org/10.1109/TED.2013.2238237

34. Danković, D., Manić, I., Stojadinović, N., Prijić, Z., Djorić-Veljković, S., Davidović, V., Prijić, A., Paskaleva, A., Spassov, D., \& Golubović, S. (2017). Modelling of threshold voltage shift in pulsed NBT stressed P-channel power VDMOSFETs. Proceedings of the International Conference on Microelectronics, MIEL, 2017-Octob, 147-151. https://doi.org/10.1109/MIEL.2017.8190089

35. Parihar, N., Goel, N., Mukhopadhyay, S., \& Mahapatra, S. (2018). BTI Analysis Tool-Modeling of NBTI DC, AC Stress and Recovery Time Kinetics, Nitrogen Impact, and EOL Estimation. IEEE Transactions on Electron Devices, 65(2), 392-403. https://doi.org/10.1109/TED.2017.2780083

36. Mahapatra, S., \& Parihar, N. (2018). A review of NBTI mechanisms and models. Microelectronics Reliability, 81, 127-135. https://doi.org/10.1016/j.microrel.2017.12.027

37. Mitrović, N., Danković, D., Prijić, Z., \& Stojadinović, N. (2019). Modelling of $\Delta V_{T}$ in NBT stressed Pchannel power VDMOSFETS. 2019 IEEE 31st International Conference on Microelectronics, MIEL 2019 - Proceedings, 177-180. https://doi.org/10.1109/MIEL.2019.8889584

38. Zafar, S., Lee, B. H., \& Stathis, J. (2004). Evaluation of NBTI in HfO2 Gate-Dielectric Stacks With Tungsten Gates. IEEE Electron Device Letters, 25(3), 153-155.

https://doi.org/10.1109/LED.2004.824244 
39. Danković, D., Manić, I., Djorić-Veljković, S., Davidović, V., Golubović, S., \& Stojadinović, N. (2009). Implications of Negative Bias Temperature Instability in Power MOS Transistors. In Micro Electronic and Mechanical Systems.

https://doi.org/10.5772/7018

40. Danković, D., Manić, I., Davidović, V., Prijić, A., Djorić-Veljković, S., Golubović, S., Prijić, Z., \& Stojadinović, N. (2012). Lifetime Estimation in NBT-stressed p-channel power VDMOSFETs. Facta Universitatis - Series: Automatic Control and Robotics, 11(1), 15-23.

41. Encyclopedia of measurement and statistics. (2007). Choice Reviews Online.

https://doi.org/10.5860/choice.44-4214

42. Hosaka, T., Nishizawa, S., Kishida, R., Matsumoto, T., \& Kobayashi, K. (2019). Compact Modeling of NBTI Replicating AC Stress / Recovery from a Single-shot Long-term DC Measurement. 2019 IEEE 25th International Symposium on On-Line Testing and Robust System Design, IOLTS 2019, July, 305-309.

https://doi.org/10.1109/IOLTS.2019.8854421

43. Baranowski, R., Firouzi, F., Kiamehr, S., Liu, C., Tahoori, M., \& Wunderlich, H. J. (2015). On-line prediction of NBTI-induced aging rates. Proceedings -Design, Automation and Test in Europe, DATE, 589-592.

https://doi.org/10.7873/date.2015.0940

44. Zahid, T., \& Li, W. (2016). A comparative study based on the least square parameter identification method for state of charge estimation of a LiFePO4 battery pack using three model-based algorithms for electric vehicles. Energies, 9(9), 736.

https://doi.org/10.3390/en9090720

Copyright $\odot 2020$ by the Authors. This is an open access article distributed under the Creative Commons Attribution (CC BY) License (https://creativecommons.org/licenses/by/4.0/), which permits unrestricted use, distribution, and reproduction in any medium, provided the original work is properly cited.

Arrived: 24. 07. 2020

Accepted: 21. 10. 2020 